\title{
Carboxymethyl Cellulose (CMC) Based Electrospun Composite Nanofiber Mats for Food Packaging
}

\author{
Motahira Hashmi ${ }^{\dagger}$, Sana Ullah ${ }^{+}$(D), Azeem Ullah (D), Yusuke Saito, Md. Kaiser Haider, Xinyu Bie, Kosei Wada \\ and Ick Soo Kim *
}

Citation: Hashmi, M.; Ullah, S.; Ullah, A.; Saito, Y.; Haider, M.K.; Bie, X.; Wada, K.; Kim, I.S. Carboxymethyl Cellulose (CMC) Based Electrospun Composite Nanofiber Mats for Food Packaging. Polymers 2021, 13, 302. https://doi.org/10.3390/ polym 13020302

Received: 4 January 2021

Accepted: 18 January 2021

Published: 19 January 202

Publisher's Note: MDPI stays neutra with regard to jurisdictional claims in published maps and institutional affiliations.

Copyright: (c) 2021 by the authors. Licensee MDPI, Basel, Switzerland. This article is an open access article distributed under the terms and conditions of the Creative Commons Attribution (CC BY) license (https:// creativecommons.org/licenses/by/ $4.0 /)$.
Nano Fusion Technology Research Group, Shinshu University Ueda Campus, Nagano 386-8567, Japan; motahirashah31@gmail.com (M.H.); sanamalik269@gmail.com (S.U.); 08tex101@gmail.com (A.U.); 19fs311d@shinshu-u.ac.jp (Y.S.); kaisershakil@yahoo.com (M.K.H.); 19fs325d@shinshu-u.ac.jp (X.B.); 20fs326h@shinshu-u.ac.jp (K.W.)

* Correspondence: kim@shinshu-u.ac.jp

+ M.H. and S.U. have same contribution in this research.

\begin{abstract}
Cellulose is one of the most abundantly available natural polymers. Carboxymethyl cellulose (CMC) belongs to the cellulose family and has different degrees of substitution. Current research comprises the fabrication and characterization of CMC nanofibers using polyvinyl alcohol (PVA) and polyvinylpyrrolidone (PVP) as capping agents and carriers for sustainable food packaging applications. Recently authors successfully fabricated smooth and uniform nanofibers of stated polymers and optimized the ratios of three polymers for continuous production. However, in this research, it was further characterized for mechanical properties, surface properties, structural properties, air permeability, and chemical properties to confirm the suitability and scope of tricomponent nanofibrous mats in food packaging applications. Different fruits and vegetables were packed in a plastic container and closed by nanofiber mats and by a plastic lid. All samples were observed after a specific period of time (fruits were kept for 40 days while vegetables were kept for 10 days in the controlled environment). It was observed in the results that fruits and vegetables closed by nanofiber based webs exhibited better freshness and lower accumulation of moisture as compared to that of containers with plastic lids. From the results of performed tests, it was observed that nanofiber mats possess enough mechanical, structural, and morphological properties to be used as food packaging.
\end{abstract}

Keywords: electrospinning; food packaging; carboxymethyl cellulose; air permeability; sustainable

\section{Introduction}

Sustainability is one of the key considerations while developing materials, methods, or systems. Materials from sustainable sources are always preferred over unsustainable materials. Natural polymers have a vast range of applications in every area of science [1-6]. However, the main problem associated with natural polymers is difficulties in processing to make them usable as useful products. Polylactic acid (PLA), chitosan [7,8], cellulose [2,3,9], zein [9], silk, and other polymers are some of the most used polymers in the field of biomedical engineering, environmental engineering, food packaging [10], tissue engineering, and other applications. Natural polymers are usually modified or blended with synthetic polymers to increase application areas due to higher productivity and smoother processing of synthetic polymers [1,7,8,11-15]. Nanofibers fabricated by either production method have multiple application areas, especially in life science (tissue engineering, biomedical engineering, including implants, wound dressing, drug delivery, etc.), food packaging, energy storage, and filters for air $[16,17]$ and water purification, and membranes. Electrospun nanofibers have also played a key role in the fight against COVID-19 [18-20]. Electrospinning is a facile and easy approach to produce fine fibers in the nanometers range [21,22]. That is why electrospun nanofibers have a wider application area as compared to that of 
melt spinning or others [23-29]. When it comes to sustainable development goals (SDGs), hygienic food availability becomes an essential consideration. Different food packaging based on natural or synthetic polymers is available in markets to preserve food for longer shelf life [30-32]. However, nanofiber based food packaging is not common due to the cost, production, and availability of nanofibrous mats [33-35]. Depending on the type of food, preservation conditions also vary. It is essential to develop functional polymers based food packaging, which can sustain in varying conditions (temperature, humidity, bio-organisms, etc.) [36-40]. CMC got the attention of researchers due to its unique characteristics and increasing demands in various applications in different areas like the food industry including food packaging, tissue engineering, drug delivery, printing, cosmetics, and dying. CMC, due to its good water interaction and water holding capacity (WHC), has also applications as absorbent. Mostly materials show better water holding capacity at high temperatures but it is the specialty of CMC that it shows excellent WHC even at low temperatures. CMC possesses excellent water absorption properties both in film and fiber form but the rate of absorption is lower in the fiber form than film. In CMC fiber absorption of $2000 \%$ of water from its initial mass has been reported while it was $6000 \%$ in case of CMC film. The presence of hydroxyl groups imparts moisture absorbing properties in CMC. The presence of -OH functionalities work as the binder (binding forces) for holding excess amount of water because of hydrogen bonding $[6,11]$.

CMC is easily soluble in water and a hydrophilic polymer. CMC is soluble in cold water and does not form a gel. There are unsubstituted sites present on the backbone of $\mathrm{CMC}$, which lowers the solubility of CMC in cold water. In cold water the unsubstituted sites of CMC do not work properly but as the water temperature goes up gel formation rate increases because of unsubstituted cellulose sites along the backbone chain as temporary cross-linkers between the chains. Viscosity of CMC and gel formation rate is directly proportional to each other. Increase in viscosity makes the CMC difficult to electrospin. PVA is well renowned polymer due to its easy spinnability, biocompatibility, and good thermo mechanical properties [41,42]. Hydroxyl groups are present on PVA, which cause inter and intramolecular hydrogen bonding. CMC and PVA together possess the strong interaction due to the hydrogen bonding. Both polymers are known for their solubility in water, which leads them towards the homogeneous solution $[8,12,43]$. PVP is famous due to its hydrophilicity. It also have good conductivity, biocompatibility, excellent filmforming properties, non-toxicity, biodegradability, and low surface tension $[7,44]$. PVP makes strong interaction with both CMC and PVA. The presence of carbonyl groups on PVP chain and hydroxyl groups on PVA chain leads them towards the strong interchain hydrogen bonding. Together CMC, PVP, and PVA possess excellent biocompatibility, biodegradability, spinnability, low surface tension, and good conductivity, which make it the most suitable material for active food packaging. There are different types of available food packaging, which include preharvest, post-harvest, active packaging, smart and intelligent packaging, and so on. All of the stated food packaging have a significant role in preserving food and maintaining freshness over a longer period of times. Our recent research targets post-harvest packaging application of electrospun nanofibers based on CMC, which is derived from a sustainable source (cellulose). Nanofibrous food packaging has a number of advantages over film based packaging due to unique morphology and a structure of nanofibrous membranes (in the results section it can be viewed by how different it is). In our previous research [45] the loading capacity of CMC was optimized for smooth nanofiber production without beads formation, however, further crosslinking and practical applicability was not examined. Current research is focused on developing food packaging that is superior in terms of structural and mechanical properties and fulfilling one of the goals of SDGs, which is sustainability. The primary source of CMC is cellulose, which is a natural and sustainable polymer. Consuming cellulose in the form of nanofibers is one of the suitable ways to boost the usability of cellulose. CMC nanofibers can potentially be used as food packaging to secure food (mostly fruits and vegetables) for a longer time. 


\section{Materials and Methods}

Polyvinylpyrrolidone (PVP) (average molecular weight of 40,000 $\mathrm{g} \mathrm{mol}^{-1}$ ), polyvinyl alcohol (PVA) (average molecular of $85,000-124,000 \mathrm{~g} \mathrm{~mol}^{-1}$, hydrolyzation degree of $87-89 \%$ ), and sodium carboxymethyl cellulose (Na-CMC) (average molecular weight of 250,000 $\mathrm{g} \mathrm{mol}^{-1}$ with substitution degree of 1.2) were procured from Sigma-Aldrich (Lois, USA). Polymers were not further modified physically or chemically before using.

PVA concentration in spinning solution was fixed at $6 \% w / w$ while weight percentage of PVP was standardized at $12 \% w / w$. CMC was added in 3 different concentrations i.e., $16.6 \%, 33.4 \%$, and $50 \%$ by weight of PVA (as PVA was selected as the base material/carrier; mentioned as ratios of PVA:PVP:CMC). Added in each solution $30 \mathrm{~min}$ before electrospinning was $2 \%$ glutaraldehyde ( $25 \%$ dilution) (Table 1 shows sample details). Electrospinning conditions were set to as follows; syringe $20 \mathrm{~mL}$, stainless steel needle of 18 gauge, commercially available syringe pump (SPS series, AS One), flow rate $0.8 \mathrm{~mL} / \mathrm{h}$, tip to collector distance was kept at $14 \mathrm{~cm}$, and voltage of $20 \mathrm{kV}$ was applied. After electrospinning all samples were crosslinked by the $\mathrm{HCl}$ fume method as per our previous research [46].

Table 1. Polymer composition in tri-component composite nanofibers.

\begin{tabular}{ccccc}
\hline \multirow{2}{*}{ Sample Names } & \multicolumn{2}{c}{ Polymers' Composition (Weight \%) } & \multirow{2}{*}{ Observations } \\
\cline { 2 - 3 } & PVA & PVP & CMC & \\
\hline PVA/CMC-1 & 6 & 0 & 1 & Fibers observed \\
PVA/CMC-2 & 6 & 0 & 2 & Electrospraying (No nanofiber) \\
PVA/PVP & 6 & 12 & 0 & \\
C1P12 & 6 & 12 & 1 & Fibers observed \\
C2P12 & 6 & 12 & 2 & Fibers observed \\
C3P12 & 6 & 12 & 3 & Fibers observed \\
\hline
\end{tabular}

\section{Characterizations}

Possibility of any chemical interactions among functional sides of PVA, PVP, and CMC, PVP was examined using Fourier transform infrared spectroscopy (FTIR) with an attenuated total reflection (ATR) prestige-21 (Shimadzu, Japan). FTIR-ATR spectra were taken from wave number ranging from 600 to $4000 \mathrm{~cm}^{-1}$. Prepared nanofibers morphology was examined using the scanning electron microscope (SEM) (JSM-5300, JEOL Ltd., Osaka, Japan). Acceleration energy was kept at $10 \mathrm{kV}$ for all samples. Diameters of nanofibers were calculated by Image J. software and taking average of 50 random readings from different nanofibers from each image. The degree of hydrophilicity of prepared nanofibrous mats was confirmed by measuring the water contact angle (WCA) of each nanofibrous sample. WCA was measured by using the contact angle analyzer (Digidrop, GBX, Whitestone way, Croydon, UK). Degradation behavior of nanofibers under high temperatures was analyzed using the thermogravimetric analyzer (Thermo-plus TG 8120, Rigaku Corporation, Osaka, Japan). The thermal degradation test was carried out in ambient atmosphere (in ambient air) and static mode while the incremental rate of heating was $10{ }^{\circ} \mathrm{C} / \mathrm{min}$ in temperature range of $25-500{ }^{\circ} \mathrm{C}$. Sample weight for all specimen was $10 \mathrm{mg}$ each. Crystalline structure of $\mathrm{CMC}$ based composite nanofibers was observed by the X-ray diffraction (XRD) spectra of each sample. XRD spectra were recorded at room

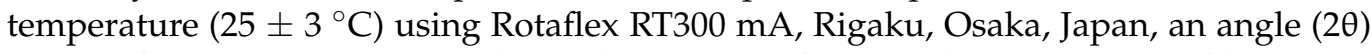
ranging from $5 \leq 2 \theta \leq 70^{\circ}$. Mechanical properties of prepared composite nanofibers were assessed by the universal testing machine (UTM), Tensilon RTC 250A; A\&D Company Ltd., Osaka, Japan. ISO 13634 testing standard was followed to prepare and characterize all specimens (note that $n=5$ for each type of nanofibers), crosshead speed was $5 \mathrm{~mm} / \mathrm{min}$ and the test was performed at room temperature. Air permeability of CMC based electrospun nanofibers was performed using Air Permeability Tester Kato Tech Co., Ltd., Osaka, Japan. Average resistance $(R)$ was calculated by measuring the AP of 5 specimens for each type of nanofibers. Suitability of electrospun nanofibers for food packaging applications was 
assessed by comparing nanofibers and plastic packaging for different fruits and vegetables in controlled environment (relative humidity $75 \%$ and temperature $2{ }^{\circ} \mathrm{C}(275 \mathrm{~K})$ ).

\section{Results and Discussions}

\subsection{Fourier Transform Infrared Spectroscopy (FTIR)}

Abundant availability of hydroxyl groups in the main chains of PVA, PVP, and CMC makes these polymers highly hydrophilic. In our recent research, FTIR spectra of uncrosslinked CMC based nanofibers have been explained [45]. However after crosslinking all nanofibrous mats were become hydrophobic because of binding of hydroxyl groups in the result of reaction supported by glutaraldehyde and $\mathrm{HCl}$. FTIR-ATR spectra in Figure 1 represents interactions among PVA, CMC, and PVP. FTIR spectra of pure CMC was taken as $C M C$ was in the powder form (because nanofibers of pure CMC were not formed), so an $-\mathrm{OH}$ peak was observed in pure $\mathrm{CMC}$ spectrum. Even after crosslinking by the $\mathrm{HCl}$ fumes method, there was still a peak of -OH bond, which is the representative peak of the hydroxyl group, and was present in the ATR spectrum of pure PVA as it can be seen in Figure 1, at a wavenumber range of $3000-3550 \mathrm{~cm}^{-1}$ a broader peak, which was associated with the hydroxyl group in PVA and CMC main chains, was observed in the ATR spectra. However, the stated peak was becoming more flatter in the case of CMC based composite nanofibers. It was concluded in the results of WCA that CMC based composite nanofibrous mats presented a bigger contact angle $\left(>90^{\circ}\right)$. Characteristic peaks of PVA were observed at $3200-3450 \mathrm{~cm}^{-1}$, which indicates the presence of the hydroxyl group (-OH stretching) in PVA chains (however limited due to crosslinking but still available). No hydroxyl peak was found in the case of a composite nanofiber, which indicates completely restricted $-\mathrm{OH}$ functionality in composite nanofibers. In the PVA spectrum, the symmetric and asymmetric peak $\left(-\mathrm{CH}_{2}-\right)$ was observed at $2900 \mathrm{~cm}^{-1}$ [46], while PVP polymer exhibited its characteristic peak of carboxylic groups' $(\mathrm{C}=\mathrm{O})$ stretching vibration in the pyrrolidone structure at $1650 \mathrm{~cm}^{-1}$, and peaks from 2850 to $2980 \mathrm{~cm}^{-1}$ were associated with $\mathrm{CH}$ stretching. Peaks at $1430 \mathrm{~cm}^{-1}$ and $1370 \mathrm{~cm}^{-1}$ were associated with the $\mathrm{CH}$ deformation band (difference in peaks in red and black colors in Figure 1). Bending vibrations of the $\mathrm{C}-\mathrm{N}$ band in pyrrolidone functionality were associated to the peaks wavenumber at $1279 \mathrm{~cm}^{-1}$. The presence of any amine groups was not found in the PVP spectrum as PVP did not show any significance peak at 3400-3500 $\mathrm{cm}^{-1}$ [47]. In conclusion of the chemical characterization, it was concluded that hydroxyl groups in main chains of stated polymers were bound because of crosslinking with the possibility of hydrogen bonding as well (however, no significance peak shift was observed except flattening of the hydroxyl peak of composite nanofibers) because significant improvement was observed in tensile and water contact angles.

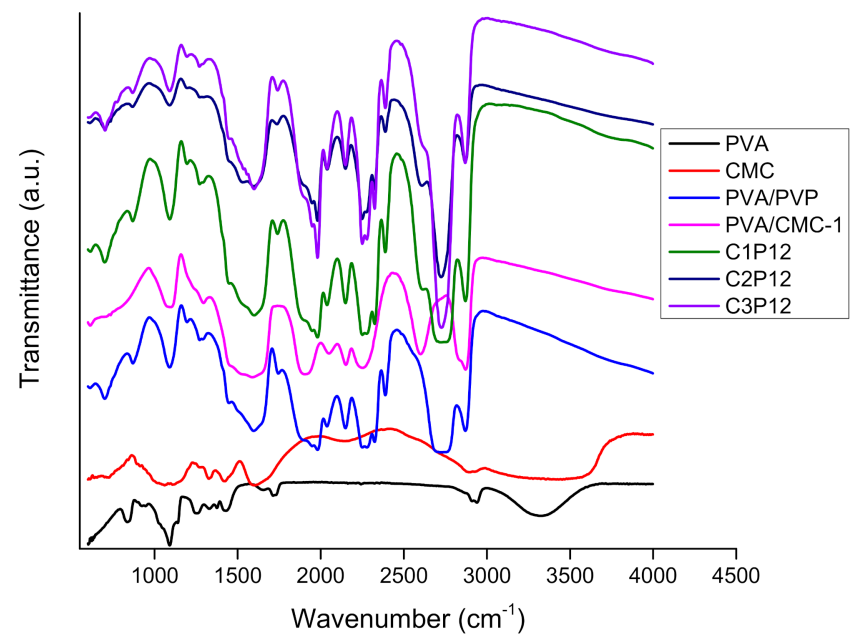

Figure 1. FTIR-ATR spectra of PVA, CMC, PVA/PVP, and tricomponent PVA/PVP/CMC electrospun nanofibers (all spectra are shifted vertically for clarity). 


\subsection{Morphological Properties}

Surface structure and diameter of nanofibers were examined by scanning electron microscope (SEM). It is already stated that it is very difficult to electrospin CMC due to its high viscosity and poor conductivity. However, PVA can be easily electrospun even at a different concentration but a concentration from $6 \%$ to $10 \%$ is the most appropriate to get smooth nanofibers. PVP possesses low viscosity at lower concentrations, which makes it difficult to electrospin. PVP helps to decrease the viscosity of CMC and imparts conductivity in it. CMC and PVP together give ideal viscosity and conductivity, which show results in the form of good nanofibers. In our recent research the concentration of PVP and CMC was optimized to obtain uniform nanofibers. SEM images of CMC based electrospun nanofibrous mats and neat PVA nanofibers are shown in Figure 2. It was observed that PVA/CMC-1 (PVA:CMC = 6:1) nanofibers were beads-free and smooth but as the concentration of CMC increased to $6: 2(w / w)$ not a single nanofiber was observed. Nanofibers of PVA/PVP composite were also smooth as it can be shown in Figure 2. C1P12, $\mathrm{C} 2 \mathrm{P} 12$, and $\mathrm{C} 3 \mathrm{P} 12$ are the samples with the addition of PVP in spinning solution, which impart conductivity and lower the viscosity of solution. Smooth and fine nanofibers can be observed from Figure 2. In the final remarks of morphological characterization, it can be stated that maximum and optimum loading capacity for CMC was up to $50 \%(w / w)$ of its carrier PVA. So, the authors recommended that PVA:PVP:CMC $=6: 12: 3$ concentration is most suitable for smoother and continuous nanofibers production without beads formation.
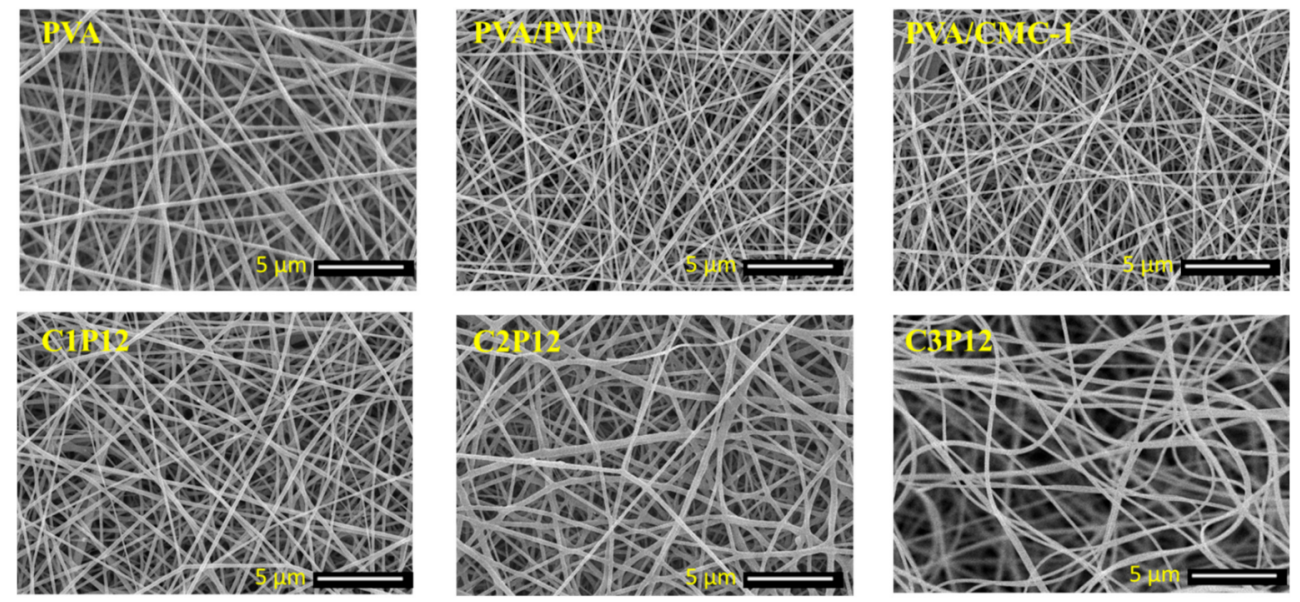

Figure 2. Scanning electron microscopic images of PVA, PVA/PVP, and tricomponent PVA/PVP/CMC nanofibers (each SEM image has a navigation bar that shows that the scale bar for all specimen was $5000 \mathrm{~nm}$ and acceleration energy was $10 \mathrm{kV}$ ).

Diameter Distribution of Nanofibers

Measuring diameters of nanofibers is one of the important tools to assess uniformity of mats. Diameters of the CMC based composite, PVA/PVP, and PVA nanofibers were calculated by taking 50 readings of random nanofibers using Image J. software. Figure 3 (histograms) shows the distribution of diameters of each nanofibrous mat. PVA is easily electrospun and yields uniform nanofibers with smaller diameter. However, crosslinked PVA exhibited a slight higher diameter with an average of approximately $120 \mathrm{~nm}$. It was observed that PVA/CMC-1 nanofibers also presented a uniform diameter range starting from 80 to the maximum diameter of approximately $180 \mathrm{~nm}$ with an average diameter of $120 \mathrm{~nm}$, which was also an indication towards successful nanofibers production using the stated ratios of PVA and MC. Inversely, no nanofiber was observed in case of PVA/CMC2 (having PVA:CMC $=6: 2$ ) rather it was rather electrosprayed. PVA/PVP nanofibers were also uniform however these nanofibers had a larger diameter than that of pure PVA and PVA/CMC nanofibers. Tricomponent nanofibers C1P12, C2P12, and C3P12 also exhibited uniform diameters ranging from 50 to $400 \mathrm{~nm}$. Slight diversity was observed 
due to variation in viscosity and conductivity of solution caused by varying concentration of CMC. It was concluded that samples having $12 \%$ PVP and varying concentration of CMC (1-3 weight \%) exhibited uniform nanofibers without beads formation, and uniform diameter distribution.
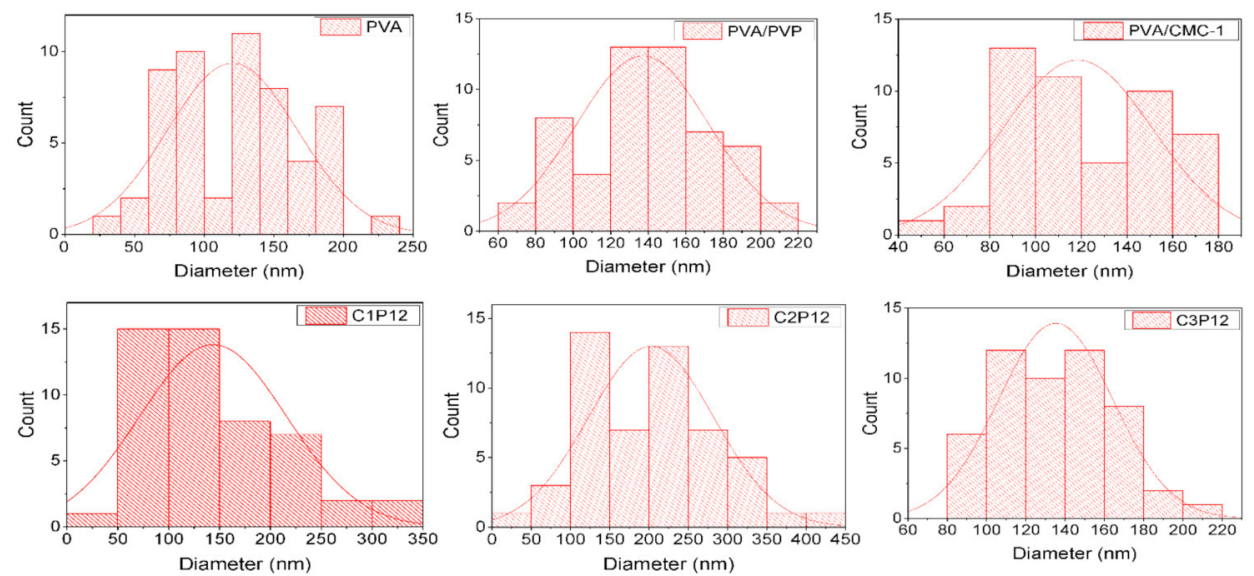

Figure 3. Diameter distribution of PVA, PVA/PVP, and tricomponent PVA/PVP/CMC nanofibers (the $\mathrm{X}$-axis shows the diameter in $\mathrm{nm}$, while the $\mathrm{Y}$-axis shows the number of fibers in that diameter range).

\subsection{Air Permeability}

Nanofiber based food packaging have an advantage over paper based or film based food packaging because of the unique porous structure of nanofiber mats. Air permeability (AP) allows food items especially fruits and vegetables to breathe (proper inhale/exhale of oxygen and carbon dioxide), which keeps them fresh for a longer period of time. Table 2 represents air permeability of PVA, PVA/PVP, PVA/CMC, and PVA/PVP/CMC nanofiber mats. It can be observed that all samples exhibited excellent air permeability. AP values for PVA/PVP were recorded higher than other samples, which may be because of higher porosity and lower fiber density of PVA/PVP. However, PVA/PVP/CMC nanofibers also exhibited better AP, which can be considered as feasible values for food packaging applications. Air permeability never means that bacteria, viruses, or other pathogens can also pass through pores among nanofibers. Pore size of nanofiber mats is usually larger than the particle size of air and smaller than that of bacteria, viruses, and other harmful pathogens [48]. That is one of the reasons that nanofiber based food packaging will be superior to ordinary food packaging materials.

Table 2. Air permeability of PVA, PVA/PVP, and CMC based composite nanofibers.

\begin{tabular}{cc}
\hline Samples & Air Permeability (Liter/Minute) \\
\hline PVA & $37.01 \pm 2.04$ \\
PVA/PVP & $52.66 \pm 2.98$ \\
PVA/CMC-1 & $36.18 \pm 1.97$ \\
C1P12 & $42.75 \pm 2.45$ \\
C2P12 & $41.03 \pm 2.61$ \\
C3P12 & $39.81 \pm 1.87$ \\
\hline
\end{tabular}

\subsection{Water Contact Angle (WCA)}

The hydrophilic or hydrophobic nature of polymeric nanofibers plays an important role while targeting final applications [27]. Food packaging should be hydrophobic to sustain in the wet and moist environment. Hydrophilicity of substance may be analyzed by calculating the water contact angle (WCA). WCAs of crosslinked PVA, PVA/PVP, and CMC based composite nanofibers were calculated to evaluate the degree of hydrophilicity /hydrophobicity of nanofibrous mats. It was stated in the literature that nanofibers of uncrosslinked PVA tend to be hydrophilic while the water contact angle increases with an 
increasing degree of crosslinking. It also depends on the type of crosslinking agents used to crosslink PVA, and the method of crosslinking as well [46]. Figure 4 shows contact angles for each sample. It can be observed that the water contact angle of crosslinked PVA was observed at $87.7^{\circ}$ while it shows a slight decrease $\left(80.4^{\circ}\right)$ in the case of PVA/PVP nanofibers. The addition of $\mathrm{CMC}$ caused an increase in the water contact angle of nanofiber mats. WCA for PVA/CMC, C1P12, C2P12, and C3P12 were recorded at $95.3^{\circ}, 102.8^{\circ}, 100.5^{\circ}$, and $99.3^{\circ}$ respectively. An increase in the contact angle may be because of interchain and intrachain bonding of PVA, CMC, and PVP in the result of crosslinking. It was concluded that all nanofibers containing $\mathrm{CMC}$ possess enough hydrophobicity to be used in food packaging applications. However, hydrophobicity may be increased by further crosslinking of nanofibers but that will lead to the reduction of biodegradability of CMC based nanofibers.

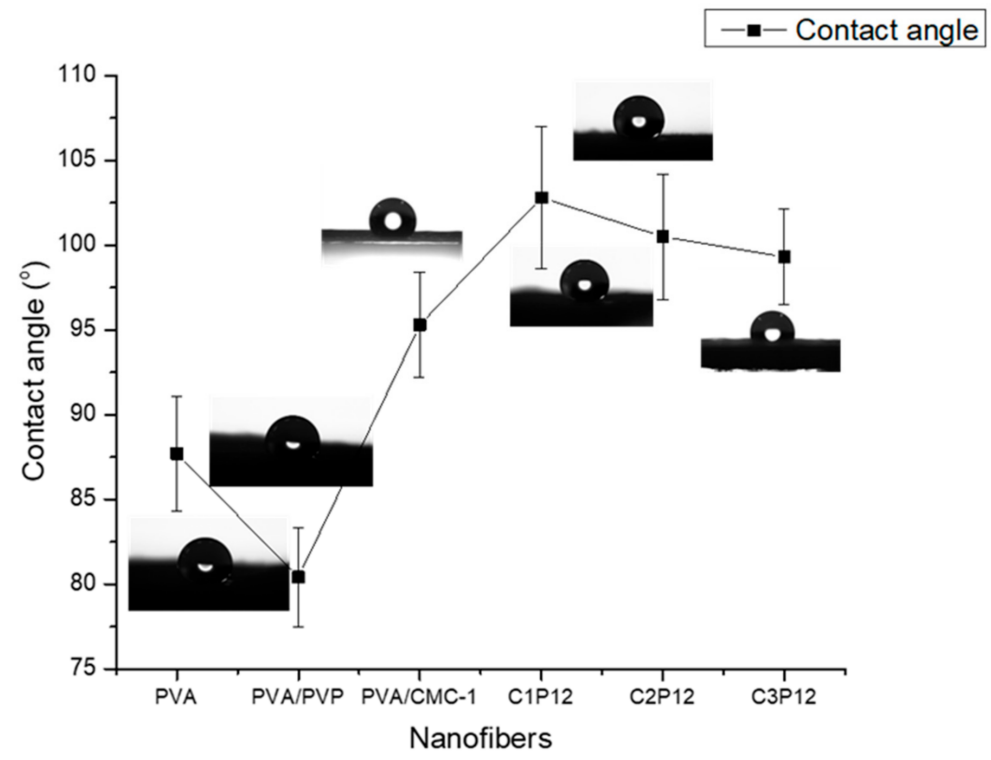

Figure 4. Water contact angles (WCA) of PVA, PVA/PVP, and CMC based composite nanofibers.

\subsection{Thermogravimetric Analysis (TGA)}

PVA and PVP show thermal stability above $300{ }^{\circ} \mathrm{C}$ while $\mathrm{CMC}$ is thermally unstable above $280^{\circ} \mathrm{C}$. Figure 5 shows TGA curves of PVA/PVP and CMC based composite nanofibers in which ratios of PVP and PVA is constant and concentration of CMC changes. Generally there are three parts of TGA plot depending on temperature zones [49]. The first zone indicates the evaporation of impurities, vapors and high volatile components and this zone is up to $100{ }^{\circ} \mathrm{C}$. The second zone shows the thermal stability of the material. It lies between onset temperatures and offset temperature. The last and third temperature zone starts from the offset temperature, which indicates the degradation of material. In the third zone, thermally unstable materials show a flatter line than the materials that are thermally stable. It can be seen that PVA/PVP nanofibrous mats show thermal stability well above $300{ }^{\circ} \mathrm{C}$ while onset temperature was dropped to $220-250{ }^{\circ} \mathrm{C}$ for nanofibers containing $\mathrm{CMC}$, which shows that addition of CMC in tricomponent nanofibrous mats caused a decrease in thermal stability of polymers. However, thermal stability up to $200{ }^{\circ} \mathrm{C}$ is good enough for food packaging application. 


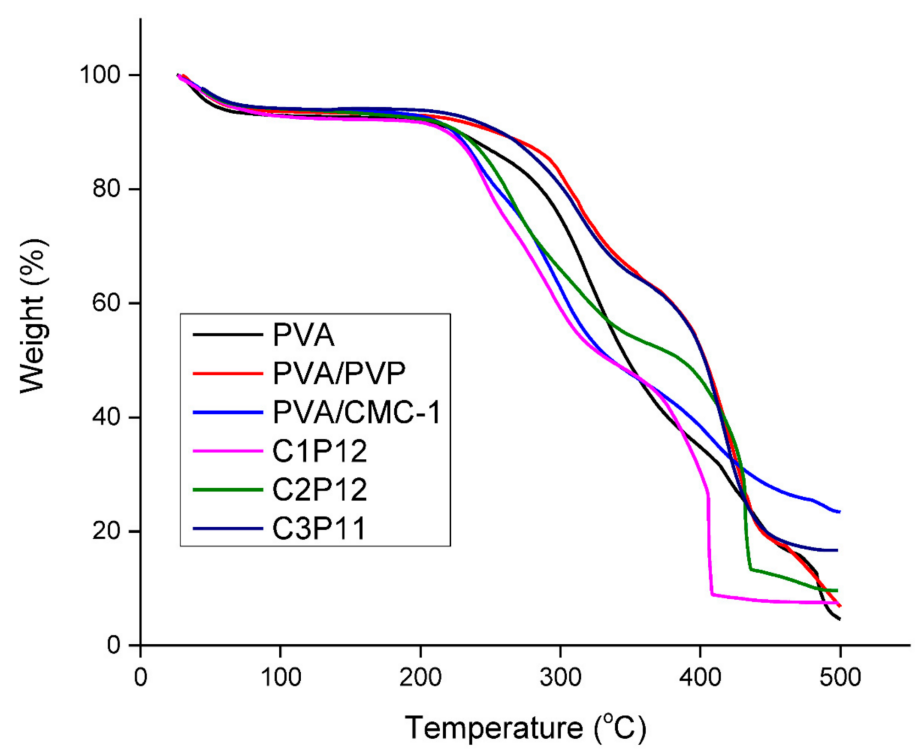

Figure 5. Thermogravimetric analyzer (TGA) plots of PVA, PVA/PVP, and CMC based composite nanofibers representing thermal degradation behavior of nanofibers.

\subsection{X-ray Diffraction (XRD)}

Crystalline structure of PVA nanofibers was compared with that of tricomponent composite nanofibers of PVA/PVP/CMC by the XRD spectra. It can be observed (Figure 6) that PVA nanofibers exhibited the characteristic peak amorphous structure of PVA at $2 \theta=19.6^{\circ}$. However the characteristic peak of PVA was suppressed by the addition of PVP, and a further shift was observed in the case of CMC addition. CMC generally exhibits its characteristic peak at $22^{\circ}$ [50] while PVP exhibits its characteristic peak at $21.84^{\circ}$ [51]. It was observed that addition of CMC caused a slight shift in peak towards $21-22^{\circ}$, which shows the dominance of CMC is tricomponent composite nanofibers. However, PVP had also a peak at $21.84^{\circ}$ [52], it could also be an effect of PVP but the intensity of tricomponent peaks tended towards CMC as shown in Figure 6. It was further evaluated for mechanical properties to conform to XRD results and it was observed that mechanical properties of nanofiber mats were also affected by the addition of CMC and PVP.

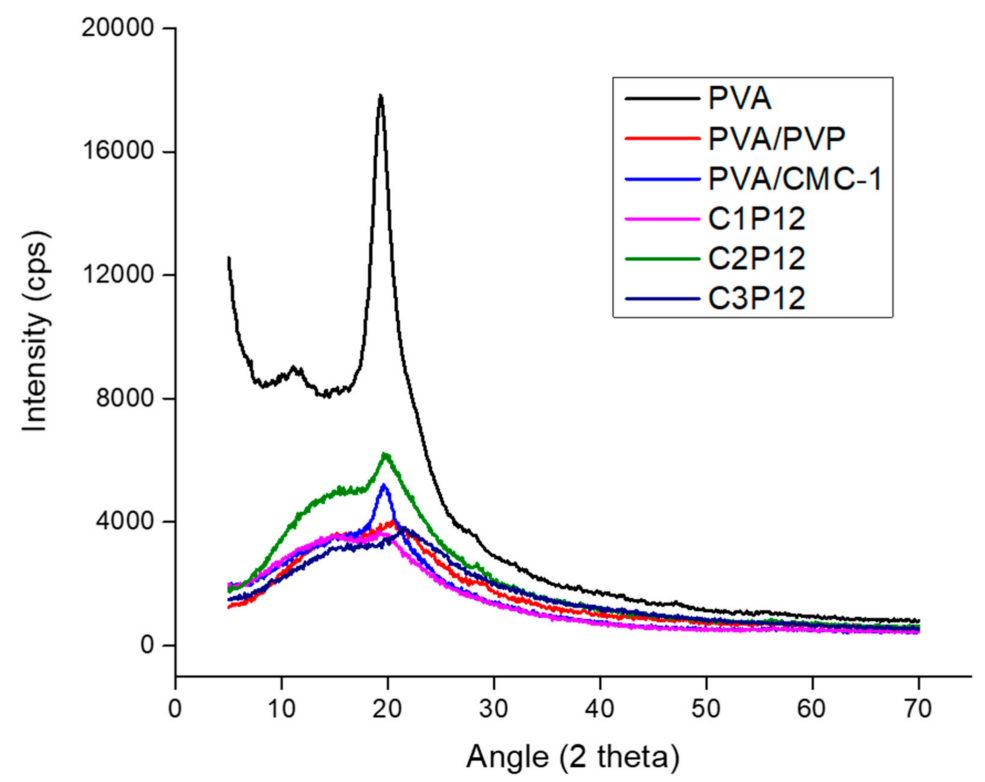

Figure 6. X-ray diffraction (XRD) spectra of PVA, PVP, and PVA/PVP/CMC nanofibers. 


\subsection{Mechanical Properties}

Mechanical properties are important for any material, which is designed for commercial applications such as packaging. Tensile strength was measured for PVA, PVA/PVP, PVA/CMC, and tricomponent PVA/PVP/CMC nanofibers, and the effect of loading of $\mathrm{CMC}$ on the mechanical properties of the final product was compared with that of pure PVA or PVA/PVP nanofibers. Table 3 represents the mechanical properties of PVA, PVA/PVP, $\mathrm{PVA} / \mathrm{CMC}$, and tricomponent PVA/PVP/CMC nanofibers. It can be shown that PVA/PVP nanofibers had significant tensile strength, however strain (elongation at break) was increased, which indicates that PVA/PVP nanofibers were more elastic than plastic. However, trends were observed to be opposite in the case of CMC. PVA/CMC nanofibers exhibited higher tensile strength (as compared to PVA/PVP nanofibers) and lower tensile strain, which indicates the presence of a crystalline lattice in the main structure of $\mathrm{CMC}$ as that of PVP. It can be observed that all samples possess good tensile strength, however tensile strength of PVA/PVP was dropped to 8.2 MPa. All other nanofiber mats exhibited a tensile strength over $10 \mathrm{MPa}$, which is considered enough in the case of nanofibers. It was also concluded that these nanofiber mats have enough mechanical strength to be used for food packaging applications.

Table 3. Tensile strength and elongation at break of PVA, PVA/PVP, PVA/CMC, and tricomponent nanofibers.

\begin{tabular}{ccc}
\hline Samples & Tensile Strength (MPa) & Elongation at Break (\%) \\
\hline PVA & $11.57 \pm 0.56$ & $22.27 \pm 3.14$ \\
PVA/PVP & $8.61 \pm 0.49$ & $31.36 \pm 2.94$ \\
PVA/CMC-1 & $11.37 \pm 0.48$ & $18.91 \pm 2.47$ \\
C1P12 & $10.29 \pm 0.37$ & $29.91 \pm 3.89$ \\
C2P12 & $10.33 \pm 0.6$ & $25.91 \pm 2.97$ \\
C3P12 & $11.05 \pm 0.58$ & $20.38 \pm 3.09$ \\
\hline
\end{tabular}

\subsection{Compatibility Study (Food Packaging)}

An experimental study was carried out to investigate suitability potential of nanofibers based food packaging by comparing with plastic based packaging. Fruits and vegetables of a similar type and freshness were taken and packed in different containers. One container for each type was packed by the plastic lid and the other was packed by nanofiber mats (C1P13 samples were used in this experiment, nanofiber based containers have white fibrous mats fixed in red bordered lids). All samples were placed in a controlled environment in the same refrigerator. Vegetables were examined after 10 days while fruits were placed for 40 days. Figure 7 shows the results obtained by the experiment. It can be observed that fruits and vegetables packed in nanofiber based packaging were having better freshness than that packed by the plastic one. There may be several reasons behind these results and two of those are; firstly nanofibers that have excellent air permeability and secondly nanofiber mats possess excellent breathability (moisture vapor transport rate) as compared to that of the plastic sheet/film. The presence of water vapors in plastic based food packaging is circled in Figure 7, which supports our claim. It can be concluded that nanofibers based food packaging is superior to conventional food packaging, and it can significantly enhance shelf life of fruits and vegetables. 


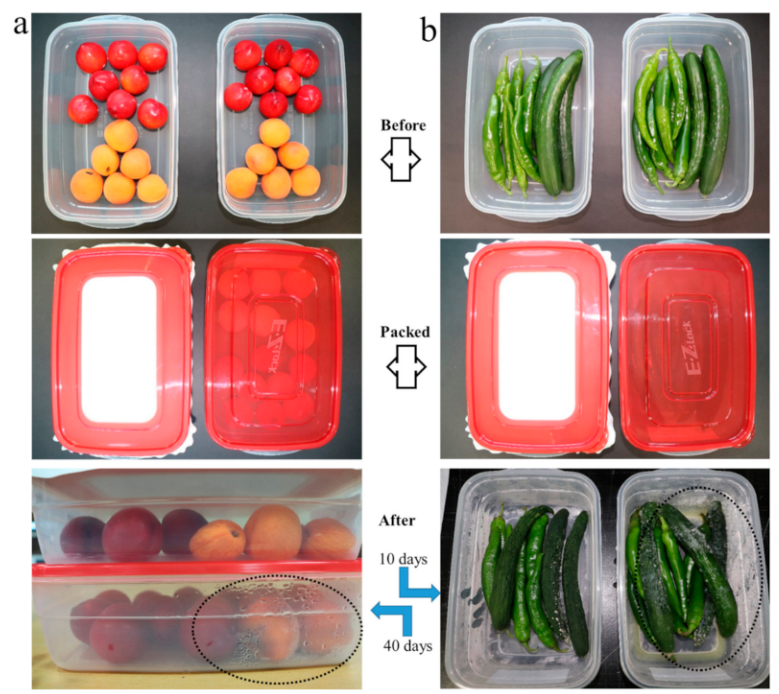

Figure 7. Real time observatory experiments for suitability of nanofibers based food packaging (a) for fruits up to 40 days and (b) for vegetables up to 10 days; relative humidity was $75 \%$ at $2{ }^{\circ} \mathrm{C}$ temperature (containers with red translucent lids are plastic based, while white lids represent nanofibers based lids.)

\section{Conclusions}

CMC was selected as a target material for electrospun nanofiber based food packaging due to biocompatibility, biodegradability, and sustainability. From the results of morphological characterization, it was concluded that CMC could be electrospun along with PVA and PVP, and possess uniform morphology. Diameters were also found to be in uniform range. The water contact angle was also measured to confirm the stability of nanofibrous mats in outdoor use. It was concluded that all nanofibers were found to be hydrophobic. It was because of crosslinking of PVA, PVP, and CMC. In general all these polymers are hydrophilic and water soluble in the uncrosslinked form, however, these were transformed to being water insoluble and hydrophobic due to crosslinking. Tensile properties were also found to be conformed to the target application as all nanofibers of the tricomponent blend had tensile strengths well above $10 \mathrm{MPa}$. Air permeability is one of the important factors that were evaluated for nanofibrous mats and it was concluded that all nanofibrous mats possess excellent air permeability, which will keep fruits and vegetable fresh for a longer time. It was also observed in the results that fruits and vegetables closed by nanofibers based webs exhibited better freshness and lower accumulation of moisture in the containers. Considering all results it is suggested that PVA/PVP/CMC nanofibrous mats can be used for food packaging.

Author Contributions: Conceptualization, M.H. and S.U.; methodology, M.H.; software, S.U.; validation, I.S.K.; formal analysis, A.U., M.K.H. and Y.S.; investigation, S.U. and X.B.; resources, I.S.K.; data curation, S.U. and K.W.; writing-original draft preparation, M.H. and S.U.; writing-review and editing, S.U.; visualization, I.S.K.; supervision, I.S.K.; project administration, I.S.K.; funding acquisition, I.S.K. All authors have read and agreed to the published version of the manuscript.

Funding: There was no funding received for this research.

Institutional Review Board Statement: Not applicable.

Informed Consent Statement: Not applicable.

Conflicts of Interest: The authors declare no conflict of interest.

\section{References}

1. Wutticharoenmongkol, P.; Hannirojram, P.; Nuthong, P. Gallic acid-loaded electrospun cellulose acetate nanofibers as potential wound dressing materials. Polym. Adv. Technol. 2019, 30, 1135-1147. [CrossRef] 
2. Zhu, M.; Wang, Y.; Zhu, S.; Xu, L.; Jia, C.; Dai, J.; Song, J.; Yao, Y.; Wang, Y.; Li, Y.; et al. Anisotropic, Transparent Films with Aligned Cellulose Nanofibers. Adv. Mater. 2017, 29, 1606284. [CrossRef] [PubMed]

3. Song, J.; Chen, C.; Yang, Z.; Kuang, Y.; Li, T.; Li, Y.; Huang, H.; Kierzewski, I.; Liu, B.; He, S.; et al. Highly Compressible, Anisotropic Aerogel with Aligned Cellulose Nanofibers. ACS Nano 2018, 12, 140-147. [CrossRef] [PubMed]

4. Dizge, N.; Shaulsky, E.; Karanikola, V. Electrospun cellulose nanofibers for superhydrophobic and oleophobic membranes. J. Memb. Sci. 2019, 590, 117271. [CrossRef]

5. Ci, J.; Cao, C.; Kuga, S.; Shen, J.; Wu, M.; Huang, Y. Improved Performance of Microbial Fuel Cell Using Esterified Corncob Cellulose Nanofibers to Fabricate Air-Cathode Gas Diffusion Layer. ACS Sustain. Chem. Eng. 2017, 5, 9614-9618. [CrossRef]

6. Boruvková, K.; Wiener, J.; Jakubičková, M. Preparation and properties of microporous structures based on cmc. In Proceedings of the NANOCON 2012-Conference Proceedings, 4th International Conference, Brno, Czech Republic, 23-25 October 2012; pp. 606-611.

7. Ignatova, M.; Manolova, N.; Rashkov, I. Novel antibacterial fibers of quaternized chitosan and poly(vinyl pyrrolidone) prepared by electrospinning. Eur. Polym. J. 2007, 43, 1112-1122. [CrossRef]

8. Pouranvari, S.; Ebrahimi, F.; Javadi, G.; Maddah, B. Chemical cross-linking of chitosan/polyvinyl alcohol electrospun nanofibers. Mater. Tehnol. 2016, 50, 663-666. [CrossRef]

9. Dong, H.; Strawhecker, K.E.; Snyder, J.F.; Orlicki, J.A.; Reiner, R.S.; Rudie, A.W. Cellulose nanocrystals as a reinforcing material for electrospun poly(methyl methacrylate) fibers: Formation, properties and nanomechanical characterization. Carbohydr. Polym. 2012, 87, 2488-2495. [CrossRef]

10. Ullah, S.; Hashmi, M.; Khan, M.Q.; Kharaghani, D.; Saito, Y.; Yamamoto, T.; Kim, I.S. Silver sulfadiazine loaded zein nanofiber mats as a novel wound dressing. RSC Adv. 2019, 9, 268-277. [CrossRef]

11. Zhang, J.; Jia, G.; Wanbin, Z.; Minghao, J.; Wei, Y.; Hao, J.; Liu, X.; Gan, Z.; Sun, A. Nanoencapsulation of zeaxanthin extracted from Lycium barbarum L. by complex coacervation with gelatin and CMC. Food Hydrocoll. 2021, 112, 106280. [CrossRef]

12. Tajeddin, B.; Ramedani, N. Preparation and characterization (Mechanical and water absorption properties) of CMC/PVA/clay nanocomposite films. Iran. J. Chem. Chem. Eng. 2016, 35, 9-15.

13. Park, Y.; You, M.; Shin, J.; Ha, S.; Kim, D.; Heo, M.H.; Nah, J.; Kim, Y.A.; Seol, J.H. Thermal conductivity enhancement in electrospun poly(vinyl alcohol) and poly(vinyl alcohol)/cellulose nanocrystal composite nanofibers. Sci. Rep. 2019, 9, 3026. [CrossRef] [PubMed]

14. Huan, S.; Bai, L.; Cheng, W.; Han, G. Manufacture of electrospun all-aqueous poly(vinyl alcohol)/cellulose nanocrystal composite nanofibrous mats with enhanced properties through controlling fibers arrangement and microstructure. Polymer 2016, 92, 25-35. [CrossRef]

15. Sanders, J.E.; Han, Y.; Rushing, T.S.; Gardner, D.J. Electrospinning of cellulose nanocrystal-filled poly (Vinyl alcohol) solutions: Material property assessment. Nanomaterials 2019, 9, 805. [CrossRef] [PubMed]

16. Opálková Šišková, A.; Frajová, J.; Nosko, M. Recycling of poly(ethylene terephthalate) by electrospinning to enhanced the filtration efficiency. Mater. Lett. 2020, 278, 2-4. [CrossRef]

17. Tcharkhtchi, A.; Abbasnezhad, N.; Zarbini Seydani, M.; Zirak, N.; Farzaneh, S.; Shirinbayan, M. An overview of filtration efficiency through the masks: Mechanisms of the aerosols penetration. Bioact. Mater. 2021, 6, 106-122. [CrossRef]

18. Konda, A.; Prakash, A.; Moss, G.A.; Schmoldt, M.; Grant, G.D.; Guha, S. Aerosol Filtration Efficiency of Common Fabrics Used in Respiratory Cloth Masks. ACS Nano 2020. [CrossRef]

19. Lee, S.; Cho, A.R.; Park, D.; Kim, J.K.; Han, K.S.; Yoon, I.J.; Lee, M.H.; Nah, J. Reusable Polybenzimidazole Nanofiber Membrane Filter for Highly Breathable PM2.5 Dust Proof Mask. ACS Appl. Mater. Interfaces 2019, 11, 2750-2757. [CrossRef]

20. Lepelletier, D.; Keita-Perse, O.; Parneix, P.; Baron, R.; Glélé, L.S.A.; Grandbastien, B.; Merle, V.; Vanhems, P.; Florentin, A.; Chaize, P.; et al. Respiratory protective equipment at work: Good practices for filtering facepiece (FFP) mask. Eur. J. Clin. Microbiol. Infect. Dis. 2019, 38, 2193-2195. [CrossRef]

21. Wu, J.; Wang, N.; Zhao, Y.; Jiang, L. Electrospinning of multilevel structured functional micro-/nanofibers and their applications. J. Mater. Chem. A 2013, 1, 7290-7305. [CrossRef]

22. Bhardwaj, N.; Kundu, S.C. Electrospinning: A fascinating fiber fabrication technique. Biotechnol. Adv. 2010, 28 , 325-347. [CrossRef] [PubMed]

23. Ullah, S.; Hashmi, M.; Kharaghani, D.; Khan, M.Q.; Saito, Y.; Yamamoto, T.; Lee, J.; Kim, I.S. Antibacterial properties of in situ and surface functionalized impregnation of silver sulfadiazine in polyacrylonitrile nanofiber mats. Int. J. Nanomed. 2019, 14, 2693-2703. [CrossRef] [PubMed]

24. Hashmi, M.; Ullah, S.; Kim, I.S. Copper oxide (CuO) loaded polyacrylonitrile (PAN) nanofiber membranes for antimicrobial breath mask applications. Curr. Res. Biotechnol. 2019, 1, 1-10. [CrossRef]

25. Hussain, N.; Ullah, S.; Sarwar, M.N.; Hashmi, M.; Khatri, M.; Yamaguchi, T.; Khatri, Z.; Kim, I.S. Fabrication and Characterization of Novel Antibacterial Ultrafine Nylon-6 Nanofibers Impregnated by Garlic Sour. Fibers Polym. 2020, 21, 2780-2787. [CrossRef]

26. Hashmi, M.; Ullah, S.; Kim, I.S. Electrospun Momordica Charantia Incorporated Polyvinyl Alcohol (PVA) Nanofibers for Antibacterial Applications. Mater. Today Commun. 2020, 101161. [CrossRef]

27. Hashmi, M.; Ullah, S.; Ullah, A.; Khan, M.Q.; Hussain, N.; Khatri, M.; Bie, X.; Lee, J.; Kim, I.S. An optimistic approach “from hydrophobic to super hydrophilic nanofibers" for enhanced absorption properties. Polym. Test. 2020, 90, 106683. [CrossRef] 
28. Hussain, N.; Yousif, M.; Ali, A.; Mehdi, M.; Ullah, S.; Ullah, A.; Mahar, F.K.; Kim, I.S. A facile approach to synthesize highly conductive electrospun aramid nanofibers via electroless deposition. Mater. Chem. Phys. 2020, 255, 123614. [CrossRef]

29. Ullah, A.; Ullah, S.; Khan, M.Q.; Hashmi, M.; Nam, P.D.; Kato, Y.; Tamada, Y.; Kim, I.S. Manuka honey incorporated cellulose acetate nanofibrous mats: Fabrication and in vitro evaluation as a potential wound dressing. Int. J. Biol. Macromol. 2020, 155, 479-489. [CrossRef]

30. Hernández-Nava, R.; López-Malo, A.; Palou, E.; Ramírez-Corona, N.; Jiménez-Munguía, M.T. Encapsulation of oregano essential oil (Origanum vulgare) by complex coacervation between gelatin and chia mucilage and its properties after spray drying. Food Hydrocoll. 2020, 109, 106077. [CrossRef]

31. Li, S.; Yan, Y.; Guan, X.; Huang, K. Preparation of a hordein-quercetin-chitosan antioxidant electrospun nanofibre film for food packaging and improvement of the film hydrophobic properties by heat treatment. Food Packag. Shelf Life 2020, $23,100466$. [CrossRef]

32. Boerzhijin, S.; Makino, Y.; Hirai, M.Y.; Sotome, I.; Yoshimura, M. Effect of perforation-mediated modified atmosphere packaging on the quality and bioactive compounds of soft kale (Brassica oleracea L. convar. acephala (DC) Alef. var. sabellica L.) during storage. Food Packag. Shelf Life 2020, 23, 100427. [CrossRef]

33. Duncan, T.V. Applications of nanotechnology in food packaging and food safety: Barrier materials, antimicrobials and sensors. J. Colloid Interface Sci. 2011, 363, 1-24. [CrossRef] [PubMed]

34. Kumar, P.; Mahajan, P.; Kaur, R.; Gautam, S. Nanotechnology and its challenges in the food sector: A review. Mater. Today Chem. 2020, 17, 100332. [CrossRef] [PubMed]

35. Enescu, D.; Cerqueira, M.A.; Fucinos, P.; Pastrana, L.M. Recent advances and challenges on applications of nanotechnology in food packaging. A literature review. Food Chem. Toxicol. 2019, 134, 110814. [CrossRef]

36. Kayaci, F.; Uyar, T. Electrospun zein nanofibers incorporating cyclodextrins. Carbohydr. Polym. 2012, 90, 558-568. [CrossRef]

37. Deng, L.; Li, Y.; Feng, F.; Wu, D.; Zhang, H. Encapsulation of allopurinol by glucose cross-linked gelatin/zein nanofibers: Characterization and release behavior. Food Hydrocoll. 2019, 94, 574-584. [CrossRef]

38. Deng, L.; Zhang, X.; Li, Y.; Que, F.; Kang, X.; Liu, Y.; Feng, F.; Zhang, H. Characterization of gelatin/zein nanofibers by hybrid electrospinning. Food Hydrocoll. 2018, 75, 72-80. [CrossRef]

39. Fabra, M.J.; Lopez-Rubio, A.; Lagaron, J.M. High barrier polyhydroxyalcanoate food packaging film by means of nanostructured electrospun interlayers of zein. Food Hydrocoll. 2013, 32, 106-114. [CrossRef]

40. Amjadi, S.; Almasi, H.; Ghorbani, M.; Ramazani, S. Reinforced ZnONPs/ rosemary essential oil-incorporated zein electrospun nanofibers by K-carrageenan. Carbohydr. Polym. 2020, 232, 115800. [CrossRef]

41. Kharaghani, D.; Gitigard, P.; Ohtani, H.; Kim, K.O.; Ullah, S.; Saito, Y.; Khan, M.Q.; Kim, I.S. Design and characterization of dual drug delivery based on in-situ assembled PVA/PAN core-shell nanofibers for wound dressing application. Sci. Rep. 2019, 9, 12640. [CrossRef]

42. Khan, M.Q.; Kharaghani, D.; Nishat, N.; Sanaullah; Shahzad, A.; Hussain, T.; Kim, K.O.; Kim, I.S. The fabrications and characterizations of antibacterial PVA/Cu nanofibers composite membranes by synthesis of $\mathrm{Cu}$ nanoparticles from solution reduction, nanofibers reduction and immersion methods. Mater. Res. Express 2019, 6, 075051. [CrossRef]

43. Khan, M.; Kharaghani, D.; Ullah, S.; Waqas, M.; Abbasi, A.; Saito, Y.; Zhu, C.; Kim, I. Self-Cleaning Properties of Electrospun PVA/TiO2 and PVA/ZnO Nanofibers Composites. Nanomaterials 2018, 8, 644. [CrossRef] [PubMed]

44. Golizadeh, M.; Karimi, A.; Gandomi-Ravandi, S.; Vossoughi, M.; Khafaji, M.; Joghataei, M.T.; Faghihi, F. Evaluation of cellular attachment and proliferation on different surface charged functional cellulose electrospun nanofibers. Carbohydr. Polym. 2019, 207, 796-805. [CrossRef]

45. Khan, M.Q.; Kharaghani, D.; Nishat, N.; Ishikawa, T.; Ullah, S.; Lee, H.; Khatri, Z.; Kim, I.S. The development of nanofiber tubes based on nanocomposites of polyvinylpyrrolidone incorporated gold nanoparticles as scaffolds for neuroscience application in axons. Text. Res. J. 2019, 89, 2713-2720. [CrossRef]

46. Hashmi, M.; Ullah, S.; Ullah, A.; Akmal, M.; Saito, Y.; Hussain, N.; Ren, X.; Kim, I.S. Optimized Loading of Carboxymethyl Cellulose (CMC) in Tri-component Electrospun Nanofibers Having Uniform Morphology. Polymers 2020, 12, 2524. [CrossRef]

47. Ullah, S.; Hashmi, M.; Hussain, N.; Ullah, A.; Sarwar, M.N.; Saito, Y.; Kim, S.H.; Kim, I.S. Stabilized nanofibers of polyvinyl alcohol (PVA) crosslinked by unique method for efficient removal of heavy metal ions. J. Water Process Eng. 2020, 33, 101111. [CrossRef]

48. Safo, I.A.; Werheid, M.; Dosche, C.; Oezaslan, M. The role of polyvinylpyrrolidone (PVP) as a capping and structure-directing agent in the formation of Pt nanocubes. Nanoscale Adv. 2019, 1, 3095-3106. [CrossRef]

49. Ullah, S.; Ullah, A.; Lee, J.; Jeong, Y.; Hashmi, M.; Zhu, C.; Joo, K.I.; Cha, H.J.; Kim, I.S. Reusability Comparison of Melt-Blown vs Nanofiber Face Mask Filters for Use in the Coronavirus Pandemic. ACS Appl. Nano Mater. 2020, 3, 7231-7241. [CrossRef]

50. Irfan, M.S.; Gill, Y.Q.; Ullah, S.; Naeem, M.T.; Saeed, F.; Hashmi, M. Polyaniline-NBR blends by in situ polymerization: Application as stretchable strain sensors. Smart Mater. Struct. 2019, 28, 095024. [CrossRef]

51. Abdel-Galil, A.; Ali, H.E.; Atta, A.; Balboul, M.R. Influence of nanostructured TiO 2 additives on some physical characteristics of carboxymethyl cellulose (CMC). J. Radiat. Res. Appl. Sci. 2014, 7, 36-43. [CrossRef]

52. MAQ, B.; Rahman, M.S. Improvement of Swelling Behaviour of Poly (Vinyl Pyrrolidone) and Acrylic Acid Blend Hydrogel Prepared By the Application of Gamma Radiation. Org. Chem. Curr. Res. 2015, 4, 2-9. [CrossRef] 